\title{
A TRANSFORMAÇÃO DA PAISAGEM: PLANOS DIRETORES EM ONZE MUNICÍPIOS DO ESPÍRITO SANTO, UM ESTUDO DE CASO
}

\author{
SILVA, Jonathas Magalhães Pereira da \\ Arquiteto, Docente da Faculdade de Arquitetura Anhembi-Morumbi, Doutor pala FAUUSP. \\ E-mail: jonathas@mpsassociados.com.br
}

\author{
TÂNGARI, Vera Regina \\ Arquiteta, Docente e pesquisadora da FAU/DPA/PROARQ, Doutora pela FAUUSP. \\ Email: vtangari@uol.com.br
}

\section{RESUMO}

Este artigo coloca em discussão a capacidade de ações concretas sobre os processo de transformação da paisagem, analisadas segundo o método de planejamento participativo. Acredita-se que os temas ambientais dependem do desenvolvimento de métodos de trabalho no estabelecimento de estratégias para a consolidação de uma nova realidade, isto é, de uma nova paisagem. Defende-se que qualquer ação coordenada, no sentido de recuperar ou conservar recursos naturais assim como de minimizar o impacto das ocupações humanas, necessita de um amplo debate, entendimento e participação dos diferentes setores da sociedade na leitura e conhecimento do território. Levando isso em consideração resolvemos apresentar um estudo de caso - a consultoria na capacitação de comissões locais de onze municípios para o desenvolvimento de Planos Diretores Municipais na Região Serrana do Espírito Santo- onde tivemos a oportunidade de coordenar os trabalhos junto às comissões formadas por representantes da sociedade organizada, do poder executivo e do poder legislativo de cada município.

\section{Palavras-chave: Paisagem, território, participação.}

\begin{abstract}
This paper discusses the feasibility of procedures related to the landscape changes, as analysed by the method of participatory planning. We believe that the environmental themes depend upon the development of work methods for the stablishment of concrete strategies to consolidate a new urban reality and a new landscape. We believe that any coordinate action in the direction of preserving or regenerating natural resources as well as minimizing the impact of human settlements needs an inclusive debate, understanding and participation of different groups in society, when reading and studying the territory. Taking this insights into account, we decided to present a case study - the consultantship for eleven municipal committees training activities related to the development of Municipal Directive Plans in the Espirito Santo State mountains region. In this project, we had the opportunity to coordinate the technical works with the local comittees, composed by representatatives from the public legislative sector, the public executive sector and from the organized community groups.
\end{abstract}

Key words: Landscape, territory, participation. 


\section{Introdução}

Existem palavras sábias, mas a sabedoria não é suficiente, falta ação. Jacob Levy Moreno ${ }^{1}$

A Região Serrana do Espírito Santo apresenta características físicas que definem compartimentos de paisagem bastante heterogêneos, onde verificam-se diferentes situações quanto à altimetria, que varia de 30 a $1.200 \mathrm{~m}$, sendo este fato assim como o relevo, a oferta de água e a temperatura determinantes para a produtividade de seus ecossistemas e as distintas formas de uso e ocupação do solo observadas.

O conjunto estudado de municípios da Região Serrana do Estado do Espírito Santo, conforme ilustrado na Figura 1, abarca uma área de 686.700 ha, onde se localizam, além das onze sedes municipais, quarenta e seis sedes distritais e demais núcleos urbanos espalhados pelo fundos de vales por todo da região.

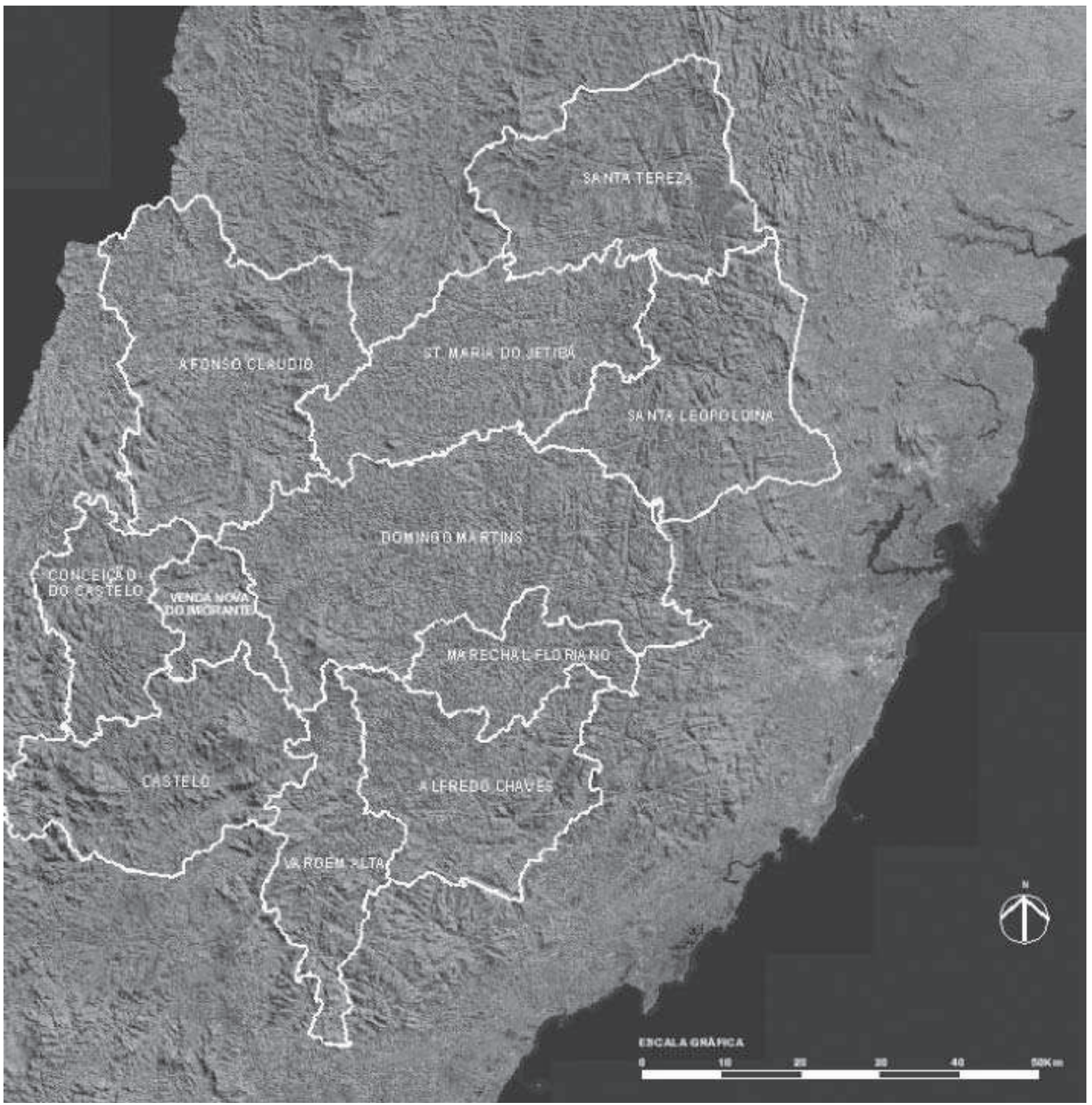

Figura 1: Mapeamento dos municípios

Fonte: Embrapa 
A alta pluviosidade regional contribui para a formação ou a alimentação de nascentes de importantes rios capixabas, como os rios Jucú, Santa Maria da Vitória, Itapemirim, Reis Magos, Santa Maria do Rio Doce, Guandu e Benevente.

As sedes municipais são de pequeno porte, sendo que a existência de vales compridos e estreitos direciona o deslocamento e a ocupação do território. Na sua maioria, as áreas urbanas da região localizam-se inicialmente nos fundos de vales, onde comumente se encontram os cursos d'água, e nas áreas onde o relevo, menos acentuado, facilita a construção das moradias, como ilustrado na Figura 2.
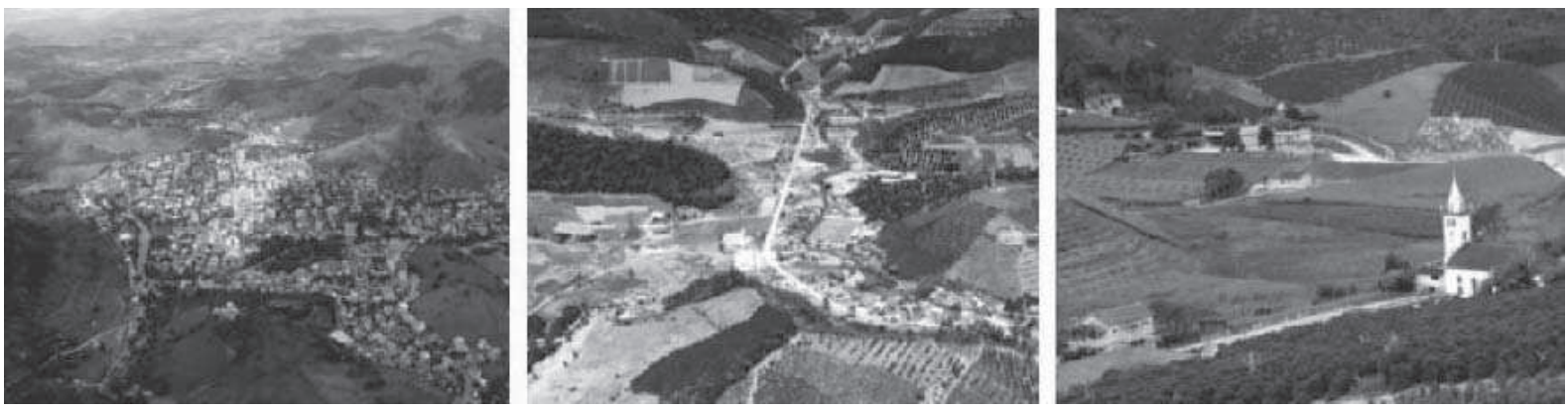

Figura 2: Cidades de Castelo, Vargem Alta e Sede Distrital de Melgaço Créditos: Fotos dos autores

Ao se analisar os resultados do processo histórico de ocupação do território, identifica-se que a ocupação dos seus antigos ambientes naturais foi iniciada no século XVI. Foi determinante nesse processo a expansão da cultura cafeeira, no período do império, quando as áreas da Região Serrana ganharam importância nos processos de desmatamento do Espírito Santo e na conseqüente simplificação ambiental deles decorrentes.

Adotou-se uma solução alternativa à mão-de-obra escrava, promovendo-se a imigração de europeus. Dessa forma, os imigrantes associados aos brasileiros que já se encontravam ali, vindos de outras regiões do país, por ocasião do ciclo do ouro ou da construção das estradas de ferro, no final do século XIX e início do XX, constituíram o mosaico cultural que hoje se verifica nessa região.

\section{O processo de ocupação e crescimentos urbanos}

De forma geral, a ocupação dos núcleos da região inicia-se normalmente em uma das margens dos rios, que só vêm a ser transpostos com o crescimento urbano. No início do processo de ocupação, as atividades agrícolas se encontram no entorno imediato da área urbana, ocupando as encostas que limitam o crescimento dos núcleos.

Com o crescimento, as cidades se adensam e inicia-se um processo de verticalização junto aos cursos d'água. Quando o fundo de vale já está ocupado e adensado inicia-se um novo movimento em direção às encostas que envolvem o núcleo urbano. Por meio de cortes e aterros conquistam-se os morros lindeiros, avançando-se sobre a área agrícola.

Os croquis da Figura 3 sintetizam esse processo.

Desta forma, o processo de ocupação da região promoveu a consolidação das áreas urbanas junto aos cursos d'água, conforme exemplificado com as imagens da cidade de Santa Tereza, na Figura 4.

Esse modelo de ocupação se baseia nas facilidades oferecidas pela proximidade dos cursos d'água considerando: o acesso a uma determinada localidade, as condições favoráveis de ocupação das áreas mais planas, a comodidade de captação d'água e a praticidade na emissão de 
esgoto sem tratamento e do lixo doméstico. Tal processo de ocupação acaba por desconsiderar as áreas de proteção permanentes - APP's - gerando sérios problemas de alagamentos nas áreas urbanas.
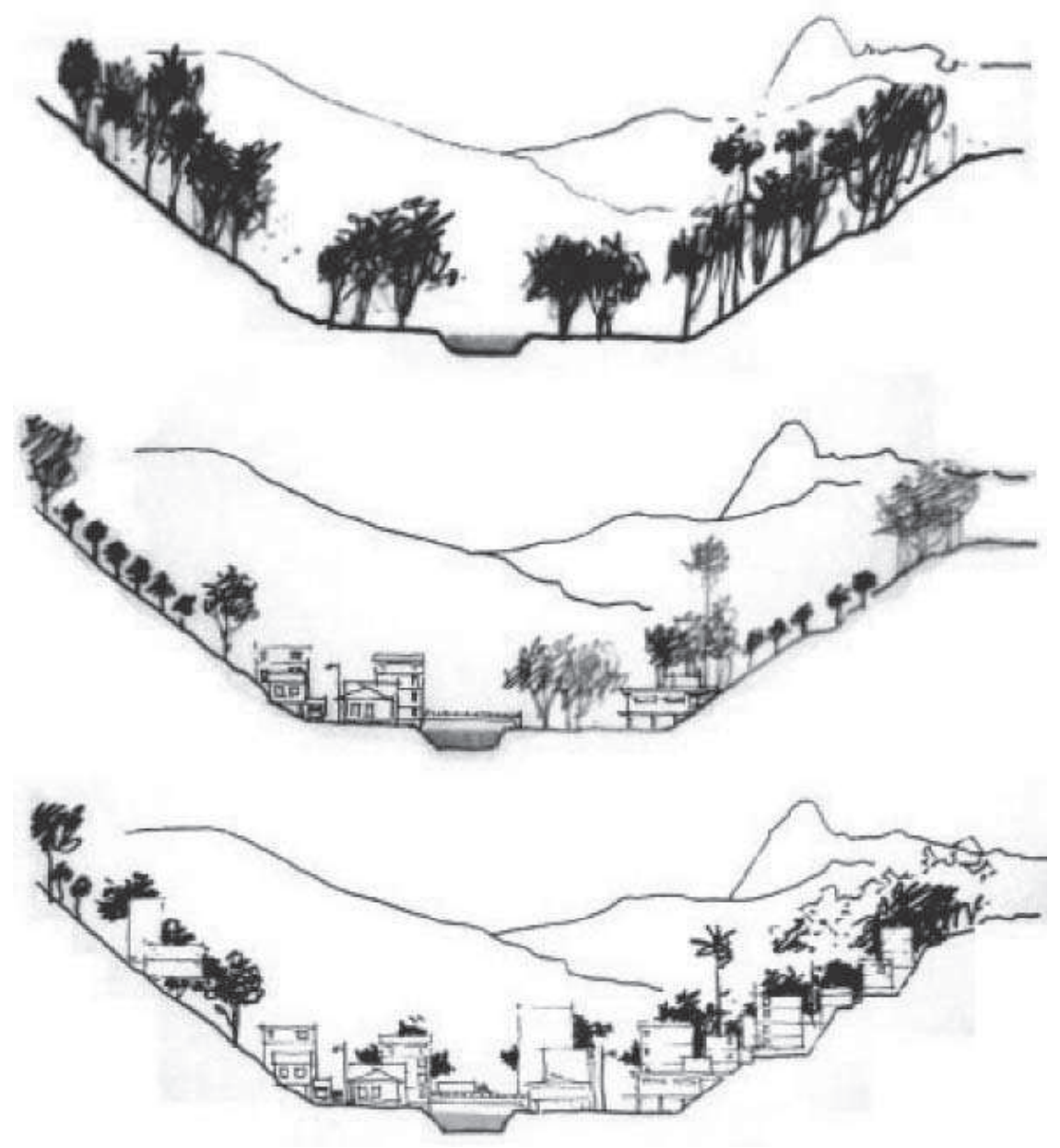

Figura 3: Croquis do processo de ocupação Crédito: Desenho de Ricardo Guerra Florez
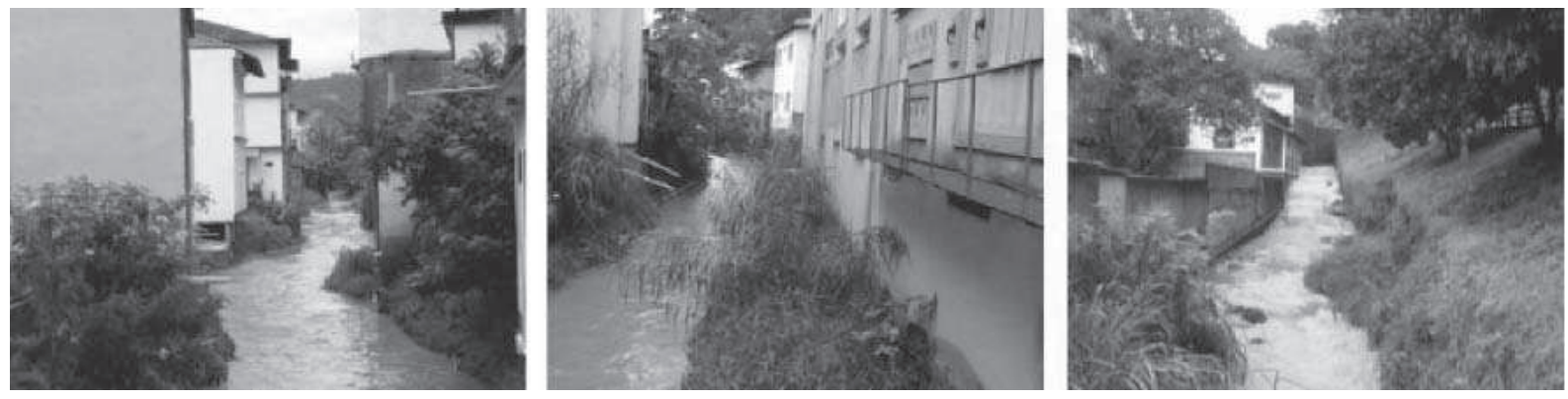

Figura 4: Sede municipal de Santa Tereza Créditos: Fotos dos autores

\section{A estrutura da paisagem, a rede de cidades e o perfil fundiário}

As áreas urbanas da Região Serrana funcionam como um ponto de apoio às atividades rurais, sendo que cada núcleo urbano tem uma área de influência sobre a população rural. Esta estrutura acaba configurando uma rede de cidades e vilas vinculadas a seu entorno rural. 
A compreensão das correlações de forças existentes sobre o território e da forma com que sua população se apropria das diferentes localidades do município se mostrou estratégica para promover a correta leitura da realidade existente nas questões relacionadas às atividades agrícolas ou ao parcelamento das terras rurais.

Para entender o parcelamento rural que ocorre na região, é necessário levar em consideração a junção de dois fatores: de um lado a dificuldade de sustentabilidade econômica das micropropriedades, e, de outro, a existência de uma pressão turística crescente, potencializada pela riqueza dos elementos naturais, como as formações rochosas indicadas na Figura 5. Estes fatores explicam a constituição de chácaras de veraneio ou até mesmo de loteamentos de características urbanas, com terrenos que variam de 250 a $3.000 \mathrm{~m}^{2}$, afastados das áreas urbanas consolidadas.

A inviabilidade econômica de produção agrícola, a dificuldade de escoamento e a quebra de valores culturais, que sustentavam os processos agrícolas de pequenas propriedades característicos da região, promoveram o fenômeno periódico de demanda por mão de obra temporária.
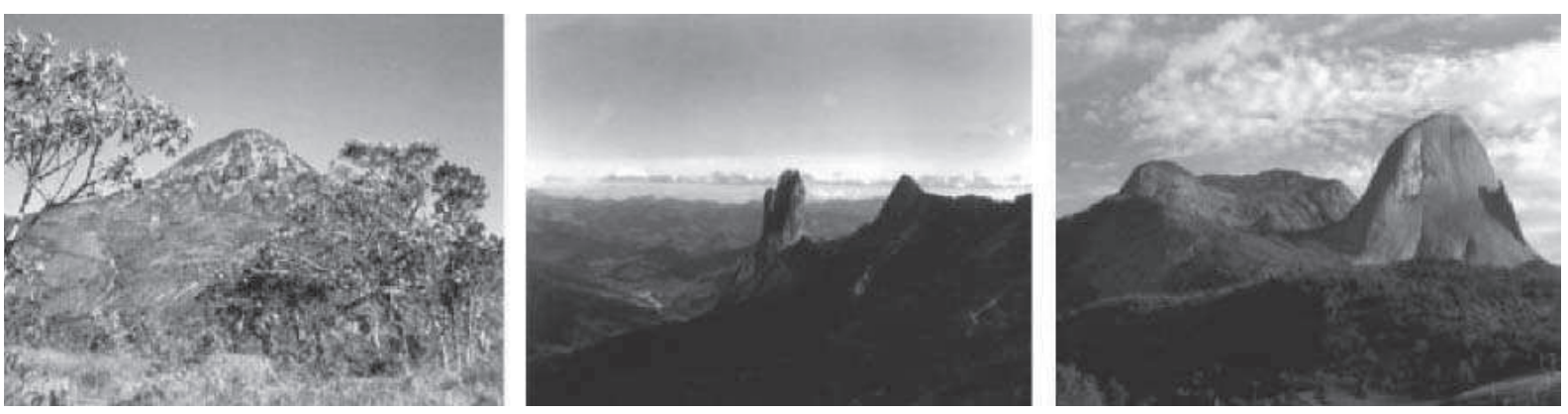

Figura 5: As formações de Forno Grand, Pontões e Pedra Azul

Créditos: Fotos dos autores

Pode-se verificar ser comum, na região estudada, a ocorrência de parcelamento de terra quando o proprietário não obtém recursos suficientes provenientes da colheita realizada, endividandose com os trabalhadores que efetivaram a colheita. Nessa situação, o proprietário cria acesso às suas terras por meio do parcelamento de uma parte das mesmas, em lotes de 50 a $100 \mathrm{~m}^{2}$, como forma de remuneração pelo trabalho de colheita realizado.

Como todo esse processo ocorre de modo informal, nos casos em que o proprietário se endivida com instituições financeiras e a garantia se faz pela terra, que informalmente não pertence mais a ele, cria-se um quadro fundiário com grande complexidade para a sua regularização.

Segundo dados do IBGE de 1996, todos os municípios da região possuíam pelo menos 78\% de seus estabelecimentos situados em terras com até 50 ha. Entretanto, se for considerada a carência da regularização fundiária na região essa situação é mais dramática.

\section{Descrição da experiência participativa}

Durante a etapa de levantamentos, realizada para o trabalho de elaboração dos planos diretores, foram lançadas algumas hipóteses sobre a ocupação da região, com o objetivo de discutir o processo e torná-lo visível a todos os participantes das comissões locais, deixando de ser um assunto de domínio apenas técnico e passando a ser incorporado pela população.

A partir das falas e argumentações dos representantes dos municípios, debateram-se as hipóteses lançadas, tendo como objetivo visibilizar o processo histórico de ocupação territorial presente na região e a relação entre as bases fundiárias existentes. 
As hipóteses promoveram um questionamento a respeito da particularidade do território da Região Serrana, investigando-se de que forma a topografia e a geomorfologia da região condicionaram a ocupação humana. Conscientes dessas características, os participantes puderam examinar como e com que intensidade os diferentes núcleos urbanos se relacionam entre si e com o entorno rural.

Foram apresentadas simulações do processo de expansão urbana em planícies em contraposição a uma ocupação de uma região montanhosa, ilustradas na Figura 6. Enquanto nos terrenos planos as áreas urbanas comumente se expandem de forma contínua, vencendo as barreiras existentes - rios, estradas, ferrovias, nas regiões montanhosas, a expansão urbana se dá de forma descontínua por meio da ocupação dos terrenos de menor inclinação normalmente localizados nos fundos de vales.
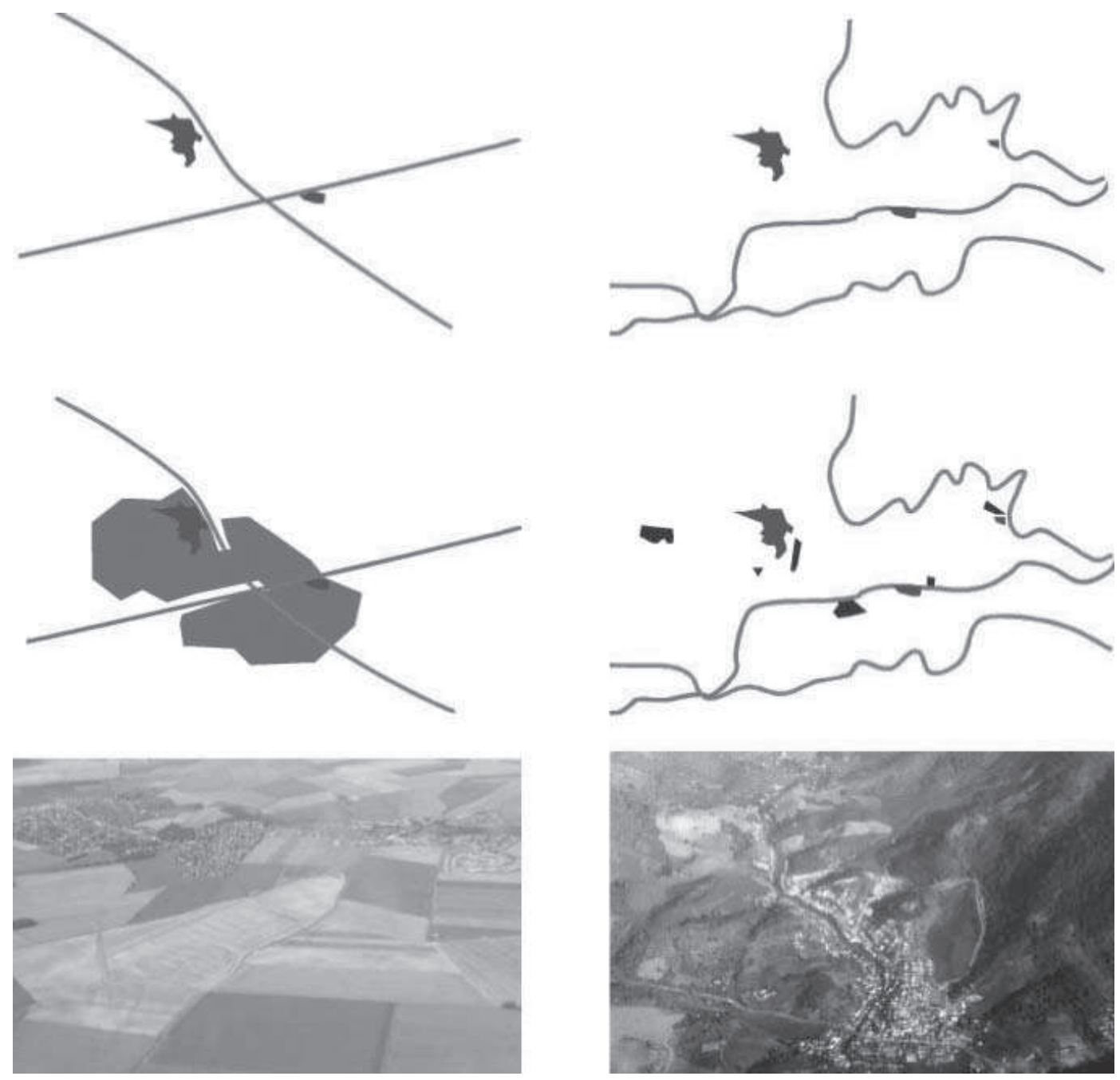

Figura 6: Simulação e exemplificação do crescimento urbano em terreno plano e em terreno montanhoso Créditos: Desenhos e fotos dos autores

As comissões locais se identificaram com a tendência de descontinuidade na ocupação do território, questionando-se sobre as conseqüências do desenrolar desse processo sem controle e parâmetros, até a sua saturação.

Para que as questões lançadas não virassem um debate teórico, a discussão realizada partiu da realidade encontrada no entorno das sedes dos municípios. Para refletir sobre os padrões de ocupação da região, a partir da base cartográfica municipal, foram mapeados todos os loteamentos, ainda não consolidados, aprovados pelas prefeituras. Constatou-se que, se todas 
as áreas dos novos loteamentos já aprovados se consolidassem, a áreas urbanas aumentariam, em alguns casos, mais de quatro vezes.

Ao longo dos debates promovidos surgiam, nas falas dos representantes das comunidades, nomes de localidades que ainda não haviam aparecido durante os trabalhos de levantamento, porém eram reconhecidos por todos. Percebeu-se a existência de uma identidade da população com áreas que foram definidas como comunidades.

Por meio do acesso ao GEOBASE - Programa de geo-processamento vinculado a institutos do Estado do Espírito Santo e de empresas privadas - foi possível obter um mapeamento das comunidades de toda a região. Esta foi uma base importante que ajudou a entender melhor o território.

Ainda que a base oferecida tenha sido construída com todo um aparato tecnológico de forma geo-referenciada, não foi apresentada à comunidade como uma "verdade inquestionável". Pelo contrário, o trabalho inicial era justamente verificar as informações ali colocadas.

Em busca do entendimento das relações que se estabeleceram em um território onde a urbanização é descontínua e sua população rural é predominante, passou-se a se identificar quais seriam as áreas de influência de cada núcleo urbano e de que forma os diferentes núcleos se relacionariam. Como essa atividade só poderia ser feita com as comissões e representantes de cada localidade, o mapeamento das áreas de influências dos núcleos acabou se tornando um mecanismo de inclusão desses representantes no processo.

Durante os trabalhos com cada comissão, corrigiram-se os nomes das comunidades que estavam errados no mapa fornecido pelo GEOBASE, assim como se questionou a existência, os limites e a divisão de algumas comunidades. Foi consenso que as áreas de influências de dos núcleos só poderiam ser definidas pelos próprios moradores dos núcleos e que as divisões de comunidades ajudavam nesse processo.

Por meio do mapeamento ficou claro que as áreas de influência dos núcleos, que compõem a rede urbana espalhada pelo território, não conhecem limites administrativos nem distritais, o que reafirmou a importância de se identificar as diferentes localidades dos municípios e suas áreas de influência para compreender a articulação regional existente.

Essa discussão possibilitou caracterizar a rede de cidades, núcleos urbanos e rurais existentes, no território municipal, identificando-se o papel de cada núcleo na rede e suas carências e potencialidades.

A identificação das centralidades urbanas do município e suas áreas de influências, conforme Figura 7, sugerem modelos de gestão e de monitoramento territorial e foram essenciais na construção das propostas de Macrozoneamento e Áreas de Planejamento promovendo a gestão territorial.

\section{O processo participativo e a leitura da paisagem}

As relações percebidas entre as áreas rurais e as áreas urbanas partiram do conhecimento da população que já se identificava com as comunidades mapeadas. $\bigcirc$ objetivo dessa leitura foi de potencializar o conhecimento já existente de forma a possibilitar a construção de modelos de gestão e de monitoramento do território.

A experiência relatada destaca o papel do corpo técnico na transformação deste conhecimento. Identifica-se uma diferente postura perante o "profissional técnico", isto é, profissional formado e habilitado para atuar em determinadas áreas do conhecimento, seja na área ambiental, da engenharia ou da arquitetura e urbanismo. 


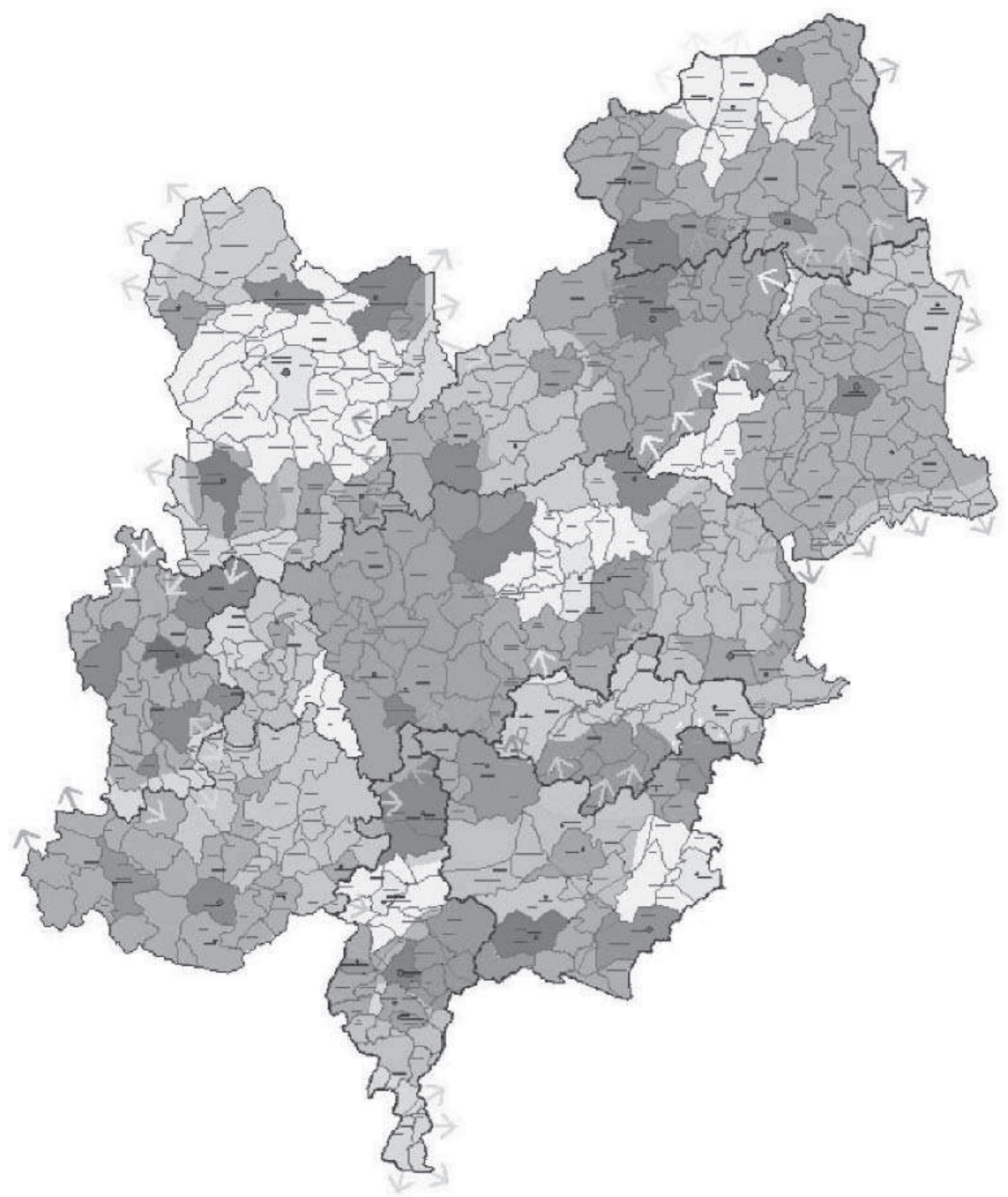

Figura 7: Mapa das centralidades e áreas de influências das áreas urbanas Crédito: Desenho dos autores 
No processo participativo, esse profissional não é considerado como "o detentor do conhecimento". O conhecimento formal que o habilita a trabalhar como profissional não o qualifica para definir soluções de forma global e específica simultaneamente.

Portanto esse profissional não está capacitado para definir soluções globais no sentido de atender as diferentes áreas, considerando os aspectos sociais, o desenvolvimento econômico, as questões ambientais e da paisagem, as questões quanto ao uso e ocupação física do território. Da mesma forma, não se qualifica para propor soluções específicas na medida em que não faz parte daquela realidade sócio-cultural e, portanto, possui uma diferente hierarquia de valores.

Dessa forma, quando as ações são cunhadas com uma visão eminentemente "técnica", a hierarquia de valores de um grupo social é imposta a outro, ao invés de essas visões contraditórias serem compartilhadas e debatidas. Nesse caso, eventualmente, as propostas são tecnicamente bem construídas, porém, freqüentemente padecem de um vício de origem por estarem descoladas da realidade presente nas comunidades em questão.

O próprio conceito de conhecimento é questionado ao se buscar a transformação de uma realidade a partir de sua compreensão. Procura-se dessa forma uma ciência dependente de uma construção social do conhecimento que abranja as condicionantes sociais, as forças econômicas e os aspectos ambientais e físico-espaciais. ${ }^{b}$

É necessário atentar ao fato de que não está se defendendo que o planejamento dispense a atuação de técnicos, que têm um papel importante na identificação de diferentes aspectos da realidade. Entretanto, acredita-se que a "Leitura Técnica" deve-se apoiar e complementar uma "Leitura Participativa", e mais, que esta leitura técnica deva ser compartilhada e debatida pelos diferentes agentes sociais sem que a tomem como uma verdade absoluta. ${ }^{c}$

Percebe-se, portanto a necessidade de o profissional - seja ele arquiteto urbanista, geógrafo, engenheiro, sociólogo, advogado - enxergar o seu papel nesse processo.

O estudo de caso apresentado indica a importância da visão "técnica" como condutor do processo, entendendo os momentos necessários de uma intervenção, de uma provocação ou no simples compartilhamento das dúvidas provenientes de questões ainda ditas de forma velada. O papel de um consultor no processo é indicar um método pelo qual seja possível explicitar os interesses contraditórios para que a realidade possa ser entendida e debatida.

\section{Conclusão}

Com a consciência das pressões e dificuldades históricas existentes e inerentes ao processo participativo, a experiência do trabalho aqui apresentada demonstra um processo em que a capacitação do cidadão possibilita a leitura da realidade e permite que o sujeito passe a interferir sobre a sua realidade, como preconizava Paulo Freire ${ }^{d}$.

O processo participativo, na fase em que nos encontramos, objetiva ser uma construção conjunta que possibilite uma leitura da realidade, na qual o sujeito passe a assumir seu papel de cidadão capaz de intervir sobre a realidade de seu mundo.

É necessário que se entenda que a Paisagem é fruto das relações sociais estabelecidas sobre um território e, portanto, a transformação da forma de apropriação dos recursos naturais e do ambiente construído dependerá desses mesmos interesses contraditórios de diferentes setores da sociedade.

Apesar de toda a técnica específica disponível, a solução para a questão ambiental não virá de uma visão fragmentária, mas sim de uma ação global, que passa necessariamente por um processo participativo onde as relações sociais que resultam na transformação constantemente da paisagem sejam explicitadas e debatidas. 


\section{Notas}

(1) Jacob Levy Moreno é o criador da Socionomia na qual o Psicodrama é uma parte de sua construção. Ciência das leis sociais e das relações, a socionomia é caracterizada fundamentalmente por seu foco na intersecção do mundo subjetivo, psicológico e do mundo objetivo, social, contextualizando o indivíduo em relação às suas circunstâncias.

(2) Sobre esse conceito, ver VYGOTSKY, L.S. Pensamento e linguagem. São Paulo: Martin Fontes, 1992.

(3) A leitura técnica e a leitura participativa são métodos preconizados no Estatuto da Cidade e na sua regulamentação. Ver BRASIL. Estatuto da cidade: Lei n. 10.257, de 10 de julho de 2001, que estabelece diretrizes gerais da política urbana. Brasília, Câmara dos Deputados, Coordenação de Publicações, 2001. e BRASIL. Plano diretor participativo: Guia para a elaboração pelos municípios e cidadãos. Brasília, Ministério das Cidades, 2004.

(4) Ver as obras do autor: FREIRE, Paulo. Educação e mudança. Rio de Janeiro: Paz e Terra, 1979; FREIRE, Paulo. Pedagogia do oprimido, Rio de Janeiro: Paz e Terra, 1987; FREIRE, Paulo. Pedagogia da autonomia. Coleção Leitura (5. ed.), São Paulo: Paz e Terra, 1996.

\section{Bibliografia}

BAKHTIN, Mikhail. Marxismo e filosofia da linguagem. São Paulo: Hucitec, 1997.

BRASIL. Estatuto da cidade: Lei n. 10.257, de 10 de julho de 2001, que estabelece diretrizes gerais da política urbana. Brasília: Câmara dos Deputados, Coordenação de Publicações, 2001. dades, 2004

Plano diretor participativo: Guia para a elaboração pelos municípios e cidadãos. Brasília: Ministério das Ci-

FREIRE, Paulo. Educação e mudança. Rio de Janeiro: Paz e Terra, 1979.

Pedagogia do oprimido, Rio de Janeiro: Paz e Terra, 1987.

Pedagogia da autonomia. 5. ed. São Paulo: Paz e Terra, 1996. (Coleção Leitura).

ESPÍRITO SANTO (Cidade). Plano de desenvolvimento sustentável da região serrana do Espírito Santo. Rio de Janeiro: Agência 21, 2004.

. Macrozoneamento da região serrana. Coordenação de Proeuts e Relações com o Mercado. Vitória, 2004.

LEFEBVRE, Henri. Lógica formal, Lógica dialética. Rio de Janeiro: Civilização Brasileira, 1983.

SANOFF, Henry. Methods of architectural programming. Stroudsburg: Dowden, Hutchinson \& Ross Inc., 1977.

SILVA, Jonathas Magalhães Pereira da Silva. O papel da disciplina de paisagismo na formação do arquiteto urbanista: 2005. Tese (Doutorado) - Faculdade de Arquitetura e Urbanismo, Universidade de São Paulo, São Paulo, 2005.

SCHÖN, Donald A. Educando o profissional reflexivo: Um novo design para o ensino e a aprendizagem. Porto Alegre: Artes Médicas Sul, 2000.

VEIGA, José Eli da et al. O Brasil rural precisa de uma estratégia de desenvolvimento. Brasília: FIPE/IICA, 2001.

VILLAÇA, Flávio. As ilusões do plano diretor. São Paulo, 2005.

VYGOTSKY, L. S. Pensamento e linguagem. São Paulo: Martin Fontes, 1992. 